\title{
More lessons for the treatment of chronic daily headache
}

\author{
Julio Pascual · Purificación Cacabelos
}

Received: 5 December 2007 / Accepted: 13 December 2007/Published online: 25 January 2008

(C) Springer-Verlag 2008

In this issue of the Journal of Headache and Pain, Yurekli et al. show that sodium valproate (VPA) is effective in the preventive treatment of chronic daily headache $(\mathrm{CDH})$ over placebo [1]. Even though the number of treated patients in their trial is not high, this study is relevant as it is the first double-blind, randomized, placebo-controlled trial with VPA. In their experience, there was a trend for a better efficacy in chronic migraine patients.

This study confirms both the previous results, obtained with open designs, with this drug [2,3] and the recent data coming from randomized, double-blind, placebocontrolled clinical trials using topiramate as the active drug [4-6]. An important conclusion of these trials is that topiramate was seen to be effective in chronic migraine patients who still met overuse criteria, which denies the idea that these patients are refractory to preventatives. Yurekli and his group do not specify whether their patients met the overuse criteria or not, but as abuse was not an exclusion reason in this trial, we can assume that at least around two-thirds were overusers as they were actively seeking consultations.

$\mathrm{CDH}$, especially chronic migraine, is one of the most disabling headaches and a frequent reason for consultation in neurology departments, accounting for at least onethird of the visits to headache centers. How should these patients be managed from a practical point of view? In our opinion, the management of these patients should not be based only on analgesic withdrawal. Rational use of acute treatment, of course, continues to be a milestone in

J. Pascual $(\bowtie) \cdot$ P. Cacabelos

Service of Neurology, University Hospital,

Paseo de San Vicente 58-182, 37007 Salamanca, Spain

e-mail: juliopascual@telefonica.net their management, trying to limit its use to $<2-3$ days/ week and avoiding abortive medications with high evidence of rebound, such as combination analgesics, opioids, and ergotics. In clinical practice, withdrawal alone is not enough for most patients and we would recommend starting preventatives from the beginning. There are now conclusive data showing that VPA and topiramate as well as amitriptyline are efficacious in $\mathrm{CDH}$ patients. No controlled results are available for other oral drugs, for instance $\beta$-blockers, but they could also be considered for this indication in clinical practice. For patients with no response to these medications, we have shown that combination therapy (a $\beta$-blocker + either VPA or topiramate) at rather low doses can be effective, possibly as they have synergistic, complementary mechanisms of action [7, 8]. Not only an early use of preventatives is important, but also a prolonged administration is usually necessary: around 50\% of responders need preventatives for periods longer than 1 year [9].

Patients with insufficient response to symptomatic medication withdrawal and oral preventatives are not rare and are very difficult to treat. Adding botulinum toxin type A injections can help these patients, as has been found in many open studies and as shown in preliminary phase II trials [10]. Finally, while waiting for more potent and specific preventatives, desperate chronic migraine patients can still be offered treatment with suboccipital stimulators, which preliminarily, have been shown to reduce the pain frequency and intensity in around three-quarters of chronic migraine patients [11].

As one of us wrote in an Editorial in this Journal 2 years ago [12], we should change the way we treat $\mathrm{CDH}$ patients. Their management is not obviously easy, but reverting a chronic migraine patient to an episodic one is highly rewarding. 


\section{References}

1. Yurekli VA, Akhan G, Kutluhan S, Uzar E, Uzar E, Koyuncuoglu HR, Gultekin F (2008) The effect of sodium valproate on chronic daily headache and its subgroups. J Headache Pain 9. 10.1007/s10194-008-0002-5

2. Mathew NT, Ali S (1991) Valproate in the treatment of persistent chronic daily headache. An open label study. Headache 31:71-74

3. Freitag FG, Diamond S, Diamond ML, Urban GJ (2001) Divalproex in the long-term treatment of chronic daily headache. Headache 41:271-278

4. Silvestrini M, Bartolini M, Coccia M, Barufaldi R, Taffi R, Provinciali L (2003) Topiramate in the treatment of chronic migraine. Cephalalgia 23:820-824

5. Silberstein SD, Lipton RB, Dodick DW, Freitag FG, Ramadan N, Mathew N, Brandes JL, Bigal M, Saper J, Ascher S, Jordan DM, Greenberg SJ, Hulihan J; Topiramate Chronic Migraine Study Group (2007) Efficacy and safety of topiramate for the treatment of chronic migraine: a randomized, double-blind, placebo-controlled trial. Headache 47:170-180

6. Diener HC, Bussone G, Van Oene JC, Lahaye M, Schwalen S, Goadsby PJ, TIPMAT-MIG 201 (TOP-CHROME) Study Group (2007) Topiramate reduces headache days in chronic migraine: a randomized, double-blind, placebo-controlled study. Cephalalgia 27:814-823

7. Pascual J, Leira R, Lainez JM (2003) Combined therapy for migraine prevention? Clinical experience with a beta-blocker plus sodium valpoate in 52 resistant migraine patients. Cephalalgia 23:961-962

8. Pascual J, Rivas MT, Leira R (2007) Testing the combination beta-blocker plus topiramate in refractory migraine. Acta Neurol Scand 115:81-83

9. Pascual J, El Berdei Y, Gómez-Sánchez JC (2007) How many migraine patients need prolonged ( $>1$ year) preventive treatment? Experience with topiramate. J Headache Pain 8:90-93

10. Dodick D, Mauskop A, Elkind AH, DeGaryse R, Brin MF, Silberstein SD, BOTOX CDH Study Group (2005) Botulinum toxin type A for the prophylaxis of chronic daily headache: subgroup analysis of patients not receiving other prophylactic medications: a randomized, double-blind, placebo controlled study. Headache 45:315-324

11. Ambrosini A (2007) Occipital nerve stimulation for intractable cluster headache. Lancet 369:163-1365

12. Pascual J (2006) Good news for chronic migraine. J Headache Pain 7:185-187 